Article published in Applied Economics Letters by Taylor \& Francis (Routledge).

Alagidede, P., Panagiotidis, T. \& Zhang, X. (2011). Why a diversified portfolio should include African assets. Applied Economics Letters, doi:10.1080/13504851.2010.537617.

http://dx.doi.org/10.1080/13504851.2010.537617 


\title{
Why a Diversified Portfolio Should Include African Assets
}

\author{
Paul Alagidede*, Theodore Panagiotidis ${ }^{\#}$ and Xu Zhang*** \\ "Department of Economics, University of Stirling, Stirling, FK9 4LA, UK \\ paul.alagidede@stir.ac.uk \\ \#Department of Economics, University of Macedonia, 540 06 Thessaloniki, Greece, \\ tpanag@uom.gr \\ ** Economic Research Institute, Guosen Research Institute, China, \\ zhangxu1@guosen.com.cn
}

\begin{abstract}
We employ parametric and non-parametric cointegration to investigate the extent of integration between African stock markets and the rest of the world. Long-run correlation estimates imply very low association between the two. The two distinct cointegration approaches confirm the latter through recursive estimation. The implication is that global market movements may have little impact on Africa. However, we argue that including African assets in a mean variance portfolio could be beneficial to international investors.
\end{abstract}

Key Words: Correlation, Long-run correlation, Cointegration, Non-parametric cointegration, African Stock Markets

JEL: C22, C52, G10 


\section{Introduction}

Since the beginning of the 1990s, a number of African countries established organised stock exchanges partly to satisfy their quest for new capital, encourage indigenisation and to incorporate elements of market capitalism into their own economies (see Singh 1999, Kim and Singal, 2000). Owing to their small size and low liquidity, significant effort has been expended in integrating Africa's capital markets. Equity market integration plays a crucial role in development. Obstfeld (1995), Bracker et al (1999), Stulz (1999) inter alia show that by dismantling investment restrictions, equity market integration allows for international risk sharing which can affect long-term economic growth by altering resource allocation and savings rates. In addition, higher degree of segmentation tends to increase the level of risk with ramifications for corporate finance and hence economic growth. In a seminal paper, Kasa (1992) argues that common stochastic trends among stock market indices can be explained through the identification of a common trend in dividends. Other factors such as geographical proximity, international trade agreements provide reasons to expect cointegration (see Portes and Rey, 2002).

However, capital market integration is not cost free as it may entail significant short-term costs $^{1}$. Stock market linkage between Africa's emerging markets and the rest of the world remain the least researched in the finance literature. This paper explores integration of Africa's emerging markets into the global financial system and the implication for portfolio diversification. For a rational institutional investor, it is important to reduce the risk of her portfolio. In the mean-variance space, the portfolio risk can be viewed as the variance of portfolio, which is constituted, by variance of each individual asset and the covariance between them. Variance is the inherent property of individual asset, and investors can reduce the portfolio variance by choosing low correlation asset combination. Therefore, the result of testing correlation may indicate the effectiveness of diversification.

\section{Methodology}

Correlation refers to co-movement in asset returns and cointegration refers to comovements in asset prices. However, correlation is a static measure of association that fails to reveal any dynamic causal relationships (see the discussion on spurious correlations in Johansen, 2007). This is of importance in finance since correlation based hedges for instance may require frequent rebalancing because there is nothing in the computation of hedge ratio to guarantee that the hedge is tied to the underlying asset over the long-term (see Alexander, 1999a and Alexander, 1999b).

We employ a nonparametric long-run correlation estimator (Albuquerque, 2008) and two distinct cointegration approaches; the Johansen (1995) trace test and the Breitung (2002) and Breitung and Taylor (2003) non-parametric test for cointegration. The former is a nonparametric long-run correlation estimator that does not suffer from misspecification problems and has a simple time domain specification. The latter has a number of advantages: Firstly, the short-run component does not affect the asymptotic null distribution of the test statistic and as a result, the test is robust against deviations from

\footnotetext{
${ }^{1}$ From the stock market crash of 1987 to the collapse of the Mexican peso in 1994, speculative attacks on the Thai baht in 1997, the Russian crisis in 1998, emerging markets jitters in May/June 2006 and the more recent sub-prime mortgage crisis, it is clear that growing interdependence could result in crisis spilling over from one country to another (see Classens and Forbes, 2001 for a survey).
} 
the usual assumption of linear short-run dynamics. Secondly, the outcome does not depend on the lag length and the inclusion of a trend or a constant. By employing this, we investigate the possibility of non-linear relationship between the markets.

\section{Data}

Our sample consists of monthly dollar prices of the Morgan Stanley Capital International Index (MSCI) for South Africa, Brazil, Mexico, Egypt and India, while for Nigeria and Kenya, the Standards and Poor (S\&P) and International Finance Corporation Global Indices (IFCG) are used ${ }^{2}$. For the developed markets we used FTSE 100, S\&P 500 and Nikkei 225 for the UK, US and Japan respectively (source: DataStream). Monthly series are used to circumvent the problem of non-synchronous trading, so common in emerging markets, and to avoid the possible effects of 'autocorrelation in volatility', a feature of high frequency data such as daily or weekly prices. Table 1 presents the summary statistics of monthly log-returns ${ }^{3}$.

\section{INSERT TABLE 1}

The mean monthly returns during the sample period are higher for the emerging economies. The standard deviation is higher for Brazil and lower for the UK. The return distribution of the developing African and Asian countries is leptokurtic.

\footnotetext{
2The MSCI is computed based on market performance and contain the largest stocks in each market. The present coverage of the IFCG Index exceeds $75 \%$ of total market capitalisation, drawing on stocks in order of their liquidity.

${ }^{3}$ The African markets in our sample are all open to foreign investors. There are no restrictions on foreign exchange transactions and repatriation of capital. Markets such as South Africa and Egypt have Global Depository Receipts that further allow foreigners to participate.
} 


\section{Empirical Results}

\section{a. Correlation}

An important feature of stock price data is the contemporaneous correlation between monthly changes in the various markets. Correlations for the entire sample period are displayed in Table 2.

\section{INSERT TABLE 2}

The average correlation among African stock returns is $0.58 \%$. This compares favourably with the average correlation for the three developed markets of $0.64 \%$ and emerging Asia and Latin America (0.6\%). South Africa, Egypt and Kenya are strongly correlated. However, the average correlation between Africa and the developed countries is $14 \%$. That of Africa and the emerging markets is only $13 \%$. This suggests that Africa's emerging markets relationship with the rest of the world can lead to significant gains in terms of portfolio diversification if these correlations were constant.

However, standard correlation measures are static and can offer misleading results as they fail to take into account longer time horizons. A long-run correlation estimator, such as the block estimator presented in Bartlett (1950), can be used to calculate the relationship between stock market returns, thus, eliminating this problem. The use of a block estimator involves the choice of interval and alignment parameters, which can be done optimally. We employ the nonparametric long-run correlation estimator proposed by Albuquerque (2008). The results together with corresponding $p$-values are presented in Tables 3 and 4.

\section{INSERT TABLES 3\&4}

With the exception of South Africa, all the other nonparametric long-run correlations appear to be very low and insignificant. Furthermore, the correlation of Nigeria and two developed countries, namely UK and US, are negative although the latter is not significant and the former is at the 1\% level. The choice of frequency was not important as we also run the test using weekly data with no qualitatively difference in the results. (See Appendix). 


\section{b. Stationarity}

We test for the order of integration using three unit roots procedures; ADF, PP and the non-parametric Breitung (2002) and find that all prices in log levels are I (1) (Table 5).

\section{INSERT TABLE 5}

\section{c. Cointegration Test}

We adopt a bivariate approach to examine the common trends between each pair of countries in our sample. The sample was partitioned to take account of the East Asian financial crisis (1997/98) and the dot com bubble (2001). With ten countries in our sample, there are 45 pairings. However, our interest is in the trends that exist between African countries and the emerging Asian and Latin American countries and the developed markets. To this end, there are 30 pairings in Table 6. 


\section{INSERT TABLE 6}

The evidence from Table 6 fails to reject the null hypothesis of no cointegration for the vast majority of the pairings. Out of 30 pairings for the entire sample, 27 pairs are noncointegrated. The first sub sample has 28 non-cointegrated cases while the last sub sample has 26. However, we cannot reject the existence of long-run relations between the following pairs: South Africa/Brazil, Egypt/Japan, and Kenya/Japan for the entire sample. In the period July 1997 to February 2000, we find only South Africa/Brazil and South Africa /UK to be bounded in the long-run. The dot com bubble seems to have much impact on the cointegration relationship between the markets than the Asian crisis.

The most interesting finding from Table 6 is that none of the African pairs is cointegrated. We can argue that geographical proximity is neither a necessary nor a sufficient condition for African stock markets to be cointegrated. This would suggest that efforts at integrating African stock markets remain largely futile to date (see Portes and Rey, 2002 for contrary evidence ${ }^{4}$ ). For the entire sample and the two sub samples, South Africa appears most integrated with other emerging countries (with Brazil and India but not Mexico). The lack of long-run relationship between African countries and the other emerging markets indicates that there are fewer spillovers of crisis from other emerging countries to Africa. This is instructive because during the South Asia financial crisis in 1997/98, only South Africa suffered from the contagion (see Kamin, 1999). The link between Africa's markets and the rest of the world is weak as is evident from our analysis. This however, does not imply that African markets would be immune in a crisis. In liquid markets, foreign portfolio investors would have withdrawn. In thinner markets though three of which are analysed here, this will not be the case.

We also perform bivariate analysis using the non-parametric Breitung (2002) cointegration test (see table 7). The Johansen trace test depends on the presence of the constant term and the number of lags, and assumes linearity. Breitung (2002) is robust to deviations of the linear short-run dynamics assumed under Johansen (1995). This allows considering the possibility of a non-linear relationship between the markets. Cointegration cannot be rejected between only i) South Africa and Egypt and ii) Egypt and Brazil. This contrasts with the Johansen test ( $p$-value of 0.188 in the first case and 0.189 in the second) which rejected cointegration between the two markets. This might imply that the relationship between these pair of stock markets might be non-linear.

\section{INSERT TABLE 7}

\footnotetext{
${ }^{4}$ In addition, Yang and Bessler (2003) analyse the relationship between five African markets and the US. The latter employs daily, whereas we used monthly returns for reasons stated earlier. Our focus is on long run relationships rather than the short run dynamics. Our period of analysis is also more recent than Yang and Bessler (2003) that does only include the late 1990s East Asian crises but also the dot com bubble.
} 
A recursive approach is also employed in the cases where cointegration was found in our sample and the two sub-samples. This would enable us to investigate how the cointegration relationship has evolved over time and identify breaks (see Hansen and Johansen, 1999). Using an expanding window, we calculate the trace test adding one observation at a time. We then divide the trace test with the critical value (obtained from MacKinnon et al., 1999). If this is above one, the null of non-cointegration is rejected and if it is below one, the null is accepted. In the case of South Africa and Brazil, no cointegration is rejected for all cases except mid 2002 where a break in the relationship is visible (Figure 1). For Egypt and Japan, no cointegration is accepted from the beginning of the sample until late 2003. From then until the end of our sample we can reject this, as it is clear that there is increased evidence of co-movement between these two markets. Similar is the evidence for Kenya and Japan. In the case of the non-parametric test, the null of no cointegration is rejected only in the last 12 months of our sample (South Africa and Egypt). The results are not qualitatively different for Egypt and Brazil.

\section{INSERT FIGURE 1}

From the perspective of the international investor, enormous potential exist to diversify into Africa. Full integration would imply that risk adjusted stock returns denominated in common currency are equal in all countries. However, given their low correlations (especially with the developed markets, see Table 2 and 3) and the weak co-movement with the rest of the world, significant gains can be made in terms of international portfolio diversification, hence including African assets in a mean variance portfolio will significantly reduce portfolio volatility and increase expected returns ${ }^{5}$.

\section{Conclusions}

This paper employed parametric and non-parametric cointegration techniques to examine the degree of integration of the African stock markets and the rest of the world. We find that there are few long-run relationships between African markets, and between Africa and the rest of the world. This implies that international stock market shocks have little effect on African stock markets, at least in the time series sense. However, fund managers seeking to diversify their assets can look up to increase the diversification of their portfolios. We also tested the long-run correlations between these countries and found the correlation between African countries and other countries are lower. It shows adding African assets into a global investment portfolio has stronger effect of risk diversification. We fail to find any significant negative long-run correlation in this study, which implies we can not minimize the variance of portfolio by investing into African assets. This paper serves a useful benchmark for future research particularly on financial integration in the broadest sense, including but not limited to the use of richer dataset such as interest rates.

\footnotetext{
${ }^{5}$ Alexander (1999b) suggests using the estimates of the cointegrating vector as weights for a long-run portfolio. However, this is not possible here since cointegration was rejected and as a result, the cointegrating vector is not available.
} 


\section{REFERENCES}

Albuquerque, P. H., 2008. Optimal Time Interval Selection in Long-Run Correlation Estimation. Mimeo, Texas A\&M International University.

Alexander, C. 1999a 'Correlation and cointegration in energy markets' in Managing Energy Price Risk (2 ${ }^{\text {nd }}$ Edition) V. Kaminsky (ed.). Risk Publications, 291-304.

Alexander, C. 1999b 'Optimal hedging using cointegration' Philosophical Transactions of the Royal Society Series A 357 2039-2058

Bartlett, M.S., 1950. Periodogram analysis and continuous spectra. Biometrika, 37, 1/2, $1-$ 16.

Bekeart G. 1995. Market Integration and Investment Barriers in Emerging Equity Markets. The World Bank Economic Review 9, 75-107.

Bekeart G. and Harvey C. 1995. Time Varying World Market Volatility. Journal of Finance 43, 29-77.

Bracker K., Dockino G., and Koch P. 1999. Economic Determinants of Evolution in International Stock Market Integration, Journal of Empirical Finance 6, 1-27.

Breitung, J. 2002. Nonparametric Tests for Unit Roots and Cointegration. Journal of Econometrics 108, 343-364.

Breitung, J. and Taylor, A.M.R 2003. Corrigendum to Nonparametric Tests for Unit Roots and Cointegration. Journal of Econometrics 117, 401-4.

Classens, S and Forbes, K (eds) 2001. International Financial Contagion: How it spreads and how it can be stopped. Kluwer Academic Publishers.

Doornik, J.A. 1998. Approximations to the asymptotic distribution of cointegration tests. Journal of Economic Surveys 12, 573-593.

Hansen, H. and Johansen, S. 1999. Some tests for parameter constancy in cointegrated VAR-models. Econometrics Journal 2, 306-333.

Johansen S. (2007) Correlation, regression and Cointegration of nonstationary economic time series, Discussion Paper 07-25, Department of Economics, University of Copenhagen.

Johansen, S. 1995. Likelihood-Based Inference in Cointegrated Vector Autoregressive Models. Oxford University Press, Oxford.

Kamin, S.B 1999. The Current International Financial Crisis: How much is New? Journal of International Money and Finance 18, 501-14

Kasa, K. 1992. Common Stochastic Trends in International Stock Markets. Journal of Monetary Economics 29, 95-124.

Kim, J., and Singal, V. 2000. Stock Market Openings: Experience of Emerging Economies. Journal of Business 73, 25-66.

Obstfeld, M. 1995. Risk-Taking, Global Diversification, Growth. American Economic Review 84, 1310-29.

Portes, R., and Rey, H., 2002. The Determinants of Cross border Equity Flows. NBER, Working Paper, Cambridge, M.A.

Singh, A. 1999. Should Africa Promote Stock Market Capitalism? Journal of International Development 11, 343-365.

Stulz, R. 1999. Globalisation of Equity Markets and Cost of Capital. Working Paper, The Ohio State University.

Wang, Z., J. Yang and D.A. Bessler. 2003. The Financial Crisis and African Stock Market Integration, Applied Economic Letters 10: 527-33 
Table 1: Summary Statistics

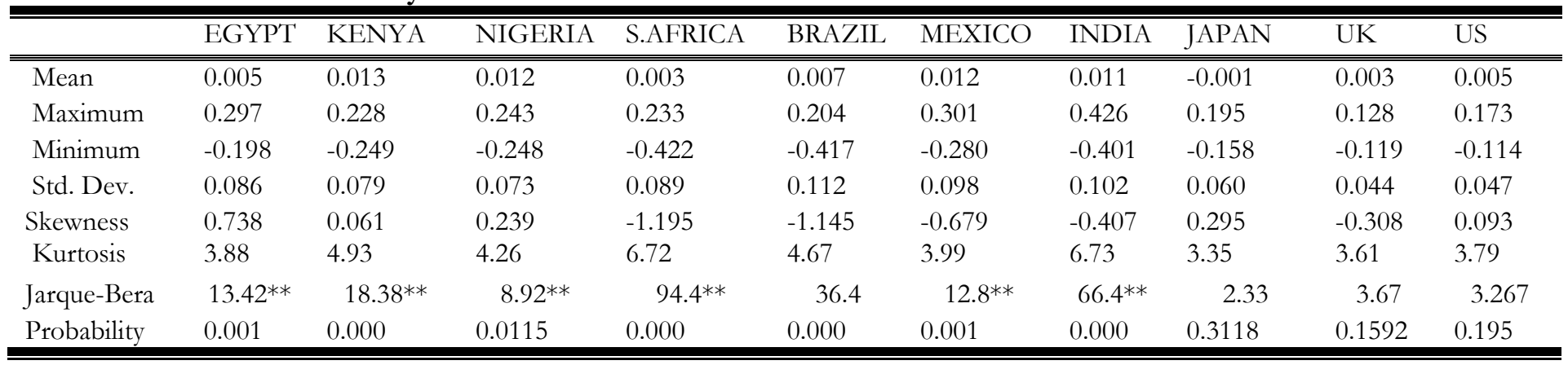

Table 2 Contemporaneous Correlations

\begin{tabular}{|c|c|c|c|c|c|c|c|c|c|c|}
\hline & EGYPT & KENYA & NIGERIA & S. AFRICA & BRAZIL & MEXICO & INDIA & $\overline{\text { JAPAN }}$ & $\overline{\mathrm{UK}}$ & US \\
\hline$\overline{\text { EGYPT }}$ & 1.000 & & & & & & & & & \\
\hline KENYA & 0.830 & 1.000 & & & & & & & & \\
\hline NIGERIA & 0.267 & 0.555 & 1.000 & & & & & & & \\
\hline SAFRICA & 0.802 & 0.733 & 0.330 & 1.000 & & & & & & \\
\hline BRAZIL & 0.688 & 0.567 & 0.246 & 0.869 & 1.000 & & & & & \\
\hline MEXICO & 0.253 & 0.343 & 0.631 & 0.462 & 0.499 & 1.000 & & & & \\
\hline INDIA & 0.361 & 0.349 & 0.310 & 0.523 & 0.489 & 0.815 & 1.000 & & & \\
\hline JAPAN & 0.298 & -0.047 & -0.612 & 0.361 & 0.473 & -0.158 & 0.135 & 1.000 & & \\
\hline $\mathrm{UK}$ & -0.049 & -0.325 & -0.632 & 0.002 & 0.211 & 0.038 & 0.299 & 0.685 & 1.000 & \\
\hline US & 0.041 & -0.106 & -0.268 & 0.094 & 0.229 & 0.421 & 0.675 & 0.407 & 0.833 & 1.00 \\
\hline
\end{tabular}

Table 3: Estimated Long-run Correlations

\begin{tabular}{lccccccccc}
\hline \hline & Egypt & Kenya & Nigeria & South Africa & Brazil & Mexico & India & Japan & UK \\
Kenya & 0.323 & & & & & & & & \\
Nigeria & -0.112 & 0.485 & & & & & & & \\
South Africa & 0.035 & 0.279 & 0.234 & & & & & & \\
Brazil & 0.117 & 0.364 & 0.178 & 0.650 & & & & & \\
Mexico & 0.037 & 0.045 & 0.184 & 0.597 & 0.734 & & & & \\
India & 0.139 & 0.314 & 0.135 & 0.552 & 0.551 & 0.650 & & & \\
Japan & 0.123 & 0.359 & 0.150 & 0.622 & 0.616 & 0.676 & 0.690 & & \\
UK & 0.035 & 0.044 & -0.173 & 0.431 & 0.587 & 0.498 & 0.420 & 0.499 & \\
US & 0.211 & 0.020 & -0.168 & 0.409 & 0.544 & 0.477 & 0.507 & 0.459 & 0.884 \\
\hline \hline
\end{tabular}

Table 4: $p$-values of the Estimated Long-run Correlations

\begin{tabular}{lccccccccc}
\hline \hline & Egypt & Kenya & Nigeria & South Africa & Brazil & Mexico & India & Japan & UK \\
Kenya & 0.034 & & & & & & & & \\
Nigeria & 0.207 & 0.006 & & & & & & & \\
South Africa & 0.379 & 0.021 & 0.019 & & & & & & \\
Brazil & 0.197 & 0.004 & 0.057 & 0.000 & & & & & \\
Mexico & 0.320 & 0.371 & 0.010 & 0.000 & 0.000 & & & & \\
India & 0.040 & 0.011 & 0.045 & 0.001 & 0.001 & 0.000 & & & \\
Japan & 0.218 & 0.012 & 0.138 & 0.002 & 0.000 & 0.000 & 0.001 & & \\
UK & 0.378 & 0.373 & 0.014 & 0.000 & 0.000 & 0.003 & 0.015 & 0.000 & \\
US & 0.030 & 0.442 & 0.068 & 0.002 & 0.000 & 0.000 & 0.002 & 0.000 & 0.000 \\
\hline \hline
\end{tabular}


Table 5: UNIT RoOT TESTS

\begin{tabular}{lcccccc}
\hline \hline & \multicolumn{2}{c}{ ADF } & \multicolumn{2}{c}{ PP } & \multicolumn{2}{c}{ Breitung } \\
\hline \hline Egypt & Levels & First Differences & Levels & First Differences & Levels & First Differences \\
Kenya & 0.0399 & $-8.6370^{* *}$ & -0.321 & $-8.702^{* *}$ & 0.02814 & 0.00983 \\
Nigeria & 1.0468 & $-9.4591^{* *}$ & 0.515 & $-9.719^{* *}$ & 0.05148 & 0.00765 \\
S. Africa & 0.6820 & $-10.071 * *$ & 0.494 & $-10.12^{* *}$ & 0.08318 & 0.00527 \\
Japan & -1.195 & $-10.327 * *$ & -1.248 & $-10.34 * *$ & 0.02250 & 0.00285 \\
UK & -1.5537 & $-10.809^{* *}$ & -1.572 & $-10.80^{* *}$ & 0.05602 & 0.00310 \\
US & -1.7628 & $-12.034 * *$ & -1.754 & $-12.02^{* *}$ & 0.03614 & 0.00188 \\
Brazil & -2.4438 & $-11.749 * *$ & -2.443 & $-11.74 * *$ & 0.01045 & 0.00243 \\
India & -0.7578 & $-10.942^{* *}$ & -0.797 & $-10.94 * *$ & 0.01587 & 0.00312 \\
Mexico & -0.2273 & $-10.10^{* *}$ & -1.009 & $-10.098^{* *}$ & 0.02861 & 0.00129 \\
\hline \hline
\end{tabular}

Note: Critical values of ADF and PP $1 \%(-3.44)$ and 5\%(-2.86) taken from MacKinnon (1991). ${ }^{* *}$ indicates significance at the $1 \%$ level, hence rejection of the null hypothesis of unit root. ADF lag length decision based on Schwartz information criterion: minimum lag $=0$ and maximum lag=12): PP bandwidth selection based on Newey-West. Critical values of Breitung $5 \%(0.01004)$ and $10 \%(0.01435)$.

Table 6: BIVARIATE JOHANSEN TEST

\begin{tabular}{|c|c|c|c|c|c|c|}
\hline & \multicolumn{2}{|c|}{ JULY 1997 FEB 06} & \multicolumn{2}{|c|}{ JUL 1997 FEB 2000} & \multicolumn{2}{|c|}{ 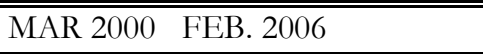 } \\
\hline & \multicolumn{2}{|l|}{ Trace test } & \multicolumn{2}{|l|}{ Trace test } & \multicolumn{2}{|l|}{ Trace test } \\
\hline & $\mathrm{H} 0: \operatorname{rank}<=0$ & H0: $\operatorname{rank}<=1$ & $\mathrm{H} 0: \operatorname{rank}<=0$ & $\mathrm{H} 0: \operatorname{rank}<=1$ & $\mathrm{H} 0: \operatorname{rank}<=0$ & $\mathrm{H} 0:$ rank $<=1$ \\
\hline South Africa/Egypt & $11.44[0.188]$ & $0.252[0.615]$ & $6.539[0.637]$ & $0.596[0.440]$ & $8.497[0.421]$ & $1.180[0.277]$ \\
\hline South Africa/Kenya & $8.966[0.375]$ & $0.152[0.696]$ & $6.802[0.606]$ & $2.410[0.121]$ & $6.371[0.656]$ & $0.148[0.700]$ \\
\hline South Africa/Nigeria & $4.235[0.878]$ & $0.018[0.891]$ & $7.829[0.491]$ & $2.465[0.116]$ & $9.848[0.298]$ & $0.184[0.668]$ \\
\hline South Africa/Brazil & $26.03[0.006] * *$ & $1.04290 .931]$ & $24.92[0.001] * *$ & $3.371[0.066]$ & $9.471[0.330]$ & $0.190[0.662]$ \\
\hline South Africa/Mexico & $5.565[0.747]$ & $0.004[0.948]$ & $9.667[0.313]$ & $3.561[0.059]$ & $6.306[0.664]$ & $0.907[0.341]$ \\
\hline South Africa/India & $7.329[0.546]$ & $0.071[0.789]$ & $6.297[0.665]$ & $2.061[0.151]$ & $15.99[0.040] *$ & $0.668[0.413]$ \\
\hline South Africa/Japan & $10.50[0.248]$ & $1.635[0.201]$ & $10.19[0.271]$ & $2.187[0.139]$ & $9.911[0.293]$ & $0.403[0.525]$ \\
\hline South Africa/UK & $7.663[0.509]$ & $2.363[0.124]$ & $13.10[0.111]$ & $5.214[0.022] *$ & $6.350[0.659]$ & $0.061[0.804]$ \\
\hline South Africa/ US & $11.64[0.177]$ & $1.943[0.163]$ & $9.325[0.342]$ & $3.736[0.053]$ & $8.837[0.388]$ & $0.087[0.767]$ \\
\hline Egypt/Kenya & $15.16[0.055]$ & $0.006[0.937]$ & $11.20[0.202]$ & $0.691[0.406]$ & $4.609[0.845]$ & $0.245[0.620]$ \\
\hline Egypt/Nigeria & $12.36[0.141]$ & $0.442[0.506]$ & $6.226[0.673]$ & $0.069[0.792]$ & $10.37[0.258]$ & $0.000[0.977]$ \\
\hline Egypt/Brazil & $11.43[0.189]$ & $0.049[0.825]$ & $4.036[0.894]$ & $0.343[0.558]$ & $12.08[0.154]$ & $0.036[0.849]$ \\
\hline Egypt/Mexico & $6.274[0.667]$ & $1.241[0.265]$ & $5.430[0.762]$ & $0.294[0.587]$ & $6.977[0.586]$ & $0.001[0.967]$ \\
\hline Egypt/India & $5.857[0.715]$ & $0.470[0.493]$ & $3.726[0.917]$ & $0.314[0.575]$ & $8.991[0.373]$ & $0.387[0.534]$ \\
\hline Egypt/Japan & $20.72[0.006] * *$ & $1.6456 \quad 0.200]$ & $4.669[0.839]$ & $0.392[0.531]$ & $10.85[0.224]$ & $0.109[0.741]$ \\
\hline Egypt/UK & $14.04[0.081]$ & $2.606[0.106]$ & $10.72[0.233]$ & $0.278[0.597]$ & $19.29[0.011] *$ & $3.050[0.081]$ \\
\hline Egypt/US & $12.62[0.130]$ & $0.344[0.557]$ & $5.063[0.801]$ & $0.468[0.494]$ & $12.26[0.146]$ & $0.045[0.832]$ \\
\hline Kenya/Nigeria & $12.03[0.157]$ & $0.883[0.347]$ & $13.49[0.097]$ & $2.644[0.104]$ & $11.31[0.195]$ & $0.366[0.545]$ \\
\hline Kenya/Japan & $25.14[0.001] * *$ & $5.21[0.022] *$ & $7.642[0.511]$ & $2.866[0.090]$ & $25.02[0.001]^{* *}$ & $3.776[0.052]$ \\
\hline Kenya/UK & $14.04[0.081]$ & $2.606[0.106]$ & $13.88[0.086]$ & $3.326[0.068]$ & $17.18[0.026] *$ & $5.257[0.022]^{*}$ \\
\hline Kenya/US & $13.19[0.108]$ & $0.246[0.620]$ & $12.42[0.139]$ & $3.201[0.074]$ & $14.51[0.069]$ & $1.385[0.239]$ \\
\hline Kenya/Brazil & $11.20[0.202]$ & $0.269[0.604]$ & $5.942[0.705]$ & $2.179[0.140]$ & $9.235[0.350]$ & $2.276[0.131]$ \\
\hline Kenya/India & $7.602[0.516]$ & $0.016[0.897]$ & $14.35[0.073]$ & $1.691[0.193]$ & $9.468[0.330]$ & $0.11[0.731]$ \\
\hline Kenya/Mexico & $9.029[0.369]$ & $2.995[0.083]$ & $10.42[0.254]$ & $2.057[0.151]$ & $6.800[0.607]$ & $0.950[0.330]$ \\
\hline Nigeria/Japan & $4.519[0.853]$ & $0.391[0.531]$ & $7.057[0.577]$ & $2.862[0.091]$ & $8.517[0.419]$ & $0.032[0.856]$ \\
\hline Nigeria/UK & $2.413[0.981]$ & $0.103[0.747]$ & $14.01[0.082]$ & $2.979[0.084]$ & $7.723[0.503]$ & $0.030[0.861]$ \\
\hline Nigeria/US & $8.571[0.414]$ & $0.019[0.889]$ & $7.396[0.539]$ & $1.269[0.260]$ & $8.820[0.389]$ & $0.141[0.707]$ \\
\hline Nigeria/Brazil & $4.095[0.890]$ & $0.008[0.927]$ & $12.34[0.142]$ & $2.533[0.111]$ & $6.649[0.624]$ & $0.205[0.650]$ \\
\hline Nigeria/India & $5.936[0.706]$ & $0.446[0.504]$ & $11.77[0.170]$ & $1.317[0.251]$ & $9.898[0.294]$ & $0.457[0.499]$ \\
\hline Nigeria/Mexico & $6.907[0.594]$ & $1.168[0.280]$ & $8.573[0.413]$ & $1.612[0.204]$ & $4.307[0.872]$ & $0.066[0.797]$ \\
\hline
\end{tabular}

Note: $p$-values from Doornik (1998); **, * denotes significance at the $1 \%$ and $5 \%$ respectively. 
Table 7: Breitung Nonparametric test

\begin{tabular}{|c|c|c|c|c|c|c|c|}
\hline & Jul'97- Feb 06 & 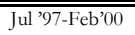 & Mar '00- Feb 06 & & Jul $97-\mathrm{Feb}^{`} 06$ & 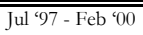 & Mar '00- Feb'06 \\
\hline & Test statistic & Test statistic & Test statistic & & Test statistic & Test statistic & Test statistic \\
\hline S.Africa/Nigeria & & & & Egypt/Mexico & & & \\
\hline$r=0 r>0$ & 73.7 & 96.4 & 74.4 & $\mathrm{r}=0 \mathrm{r}>0$ & 62.0 & 80.4 & 119.4 \\
\hline$r=1 r>1$ & 11.7 & 12.8 & 10.8 & $r=1 r>1$ & 17.4 & 18.6 & 12.6 \\
\hline S.Africa/Egypt & & & & Egypt/India & & & \\
\hline$r=0 r>0$ & $537.2^{* *}$ & 96.65 & $340.81 * *$ & $r=0 r>0$ & 84.2 & 175.9 & 79.1 \\
\hline$r=1 r>1$ & 35.0 & 15.2 & 12.6 & $r=1 r>1$ & 31.9 & 14.4 & 11.7 \\
\hline S.Africa/Kenya & & & & Nigeria/India & & & \\
\hline$r=0 r>0$ & 109 & 74.3 & 88.1 & $\mathrm{r}=0 \mathrm{r}>0$ & 131 & 60.6 & 64.5 \\
\hline$r=1 r>1$ & 18.82 & 13.7 & 11.4 & $r=1 r>1$ & 11.8 & 10.7 & 11.0 \\
\hline S.Africa/UK & & & & Nigeria/Kenya & & & \\
\hline$r=0 r>0$ & 90.23 & 98.6 & 55.2 & $r=0 r>0$ & 68.1 & 83.3 & 110.9 \\
\hline $\mathrm{r}=1 \mathrm{r}>1$ & 21.05 & 12.9 & 11.4 & $\mathrm{r}=1 \mathrm{r}>1$ & 12.0 & 11.9 & 10.6 \\
\hline S. Africa/ US & & & & Nigeria/UK & & & \\
\hline$r=0 r>0$ & 146.31 & 80.2 & 58.1 & $r=0 r>0$ & 118 & 167.5 & 57.1 \\
\hline$r=1 r>1$ & 40.99 & 10.8 & 11.7 & $r=1 r>1$ & 11.9 & 12.2 & 11.0 \\
\hline$r=0 r>0$ & 74.0 & 72.4 & 59.4 & $\mathrm{r}=0 \mathrm{r}>0$ & 111 & 89.9 & 59.6 \\
\hline$r=1 r>1$ & 12.6 & 25.2 & 10.9 & $r=1 r>1$ & 11.8 & 10.8 & 11.0 \\
\hline S.Africa/Brazil & & & & Nigeria/Japan & & & \\
\hline$r=0 r>0$ & 215.56 & 169.2 & 71.4 & $\mathrm{r}=0 \mathrm{r}>0$ & 91.7 & 60.5 & 60.9 \\
\hline$r=1 r>1$ & 43.73 & 22.0 & 14.4 & $r=1 r>1$ & 11.2 & 11.7 & 11.1 \\
\hline S.Africa/Mexico & & & & Nigeria/Brazil & & & \\
\hline $\mathrm{r}=0 \mathrm{r}>0$ & 71.34 & 69.2 & 131.2 & $r=0 r>0$ & 83.6 & 133.2 & 57.7 \\
\hline$r=1 r>1$ & 15.73 & 16.6 & 15.1 & $r=1 r>1$ & 11.5 & 12.9 & 11.1 \\
\hline S. Africa/India & & & & Nigeria/Mexico & & & \\
\hline$r=0 r>0$ & 90.77 & 67.1 & 79.7 & $r=0 r>0$ & 148.28 & 62.0 & 63.2 \\
\hline$r=1 r>1$ & 34.94 & 11.7 & 14.0 & $r=1 r>1$ & 11.86 & 12.0 & 11.0 \\
\hline Egypt/Nigeria & & & & Kenya/UK & & & \\
\hline$r=0 r>0$ & 57.47 & 97.4 & 72.6 & $r=0 r>0$ & 90.3 & 231.9 & 55.4 \\
\hline $\mathrm{r}=1 \mathrm{r}>1$ & 11.91 & 11.4 & 10.6 & $r=1 r>1$ & 15.9 & 12.5 & 10.7 \\
\hline Egypt/Kenya & & & & Kenya/Japan & & & \\
\hline$r=0 r>0$ & 65.6 & 312.7 & 92.4 & $\mathrm{r}=0 \mathrm{r}>0$ & 66.4 & 69.9 & 59.4 \\
\hline$r=1 r>1$ & 20.99 & 13.1 & 10.6 & $r=1 r>1$ & 19.3 & 190.1 & 10.7 \\
\hline Egypt/US & & & & Kenya/Brazil & & & \\
\hline$r=0 r>0$ & 135.66 & 157.3 & 56.2 & $\mathrm{r}=0 \mathrm{r}>0$ & 107 & 75.8 & 58.2 \\
\hline$r=1 r>1$ & 33.82 & 10.7 & 10.7 & $r=1 r>1$ & 17.6 & 13.2 & 11.2 \\
\hline Egypt/Japan & & & & Kenya/Mexico & & & \\
\hline$r=0 r>0$ & 59.71 & 77.1 & 56.8 & $r=0 r>0$ & 96.9 & 73.0 & 74.9 \\
\hline$r=1 r>1$ & 13.96 & 18.3 & 10.7 & $r=1 r>1$ & 15.7 & 14.7 & 11.4 \\
\hline Egypt/Brazil & & & & Kenya/India & & & \\
\hline$r=0 r>0$ & $265.98^{*}$ & 79.8 & 73.9 & $r=0 r>0$ & 124 & 147.8 & 110.9 \\
\hline$r=1 r>1$ & 35.51 & 14.2 & 11.9 & $r=1 r>1$ & 18.9 & 12.3 & 10.6 \\
\hline
\end{tabular}

Note: Critical values at $5 \%$ are 329.9 and 261 at the $10 \%$. 
Figure 1.Recursive Estimation

a) Johansen Test
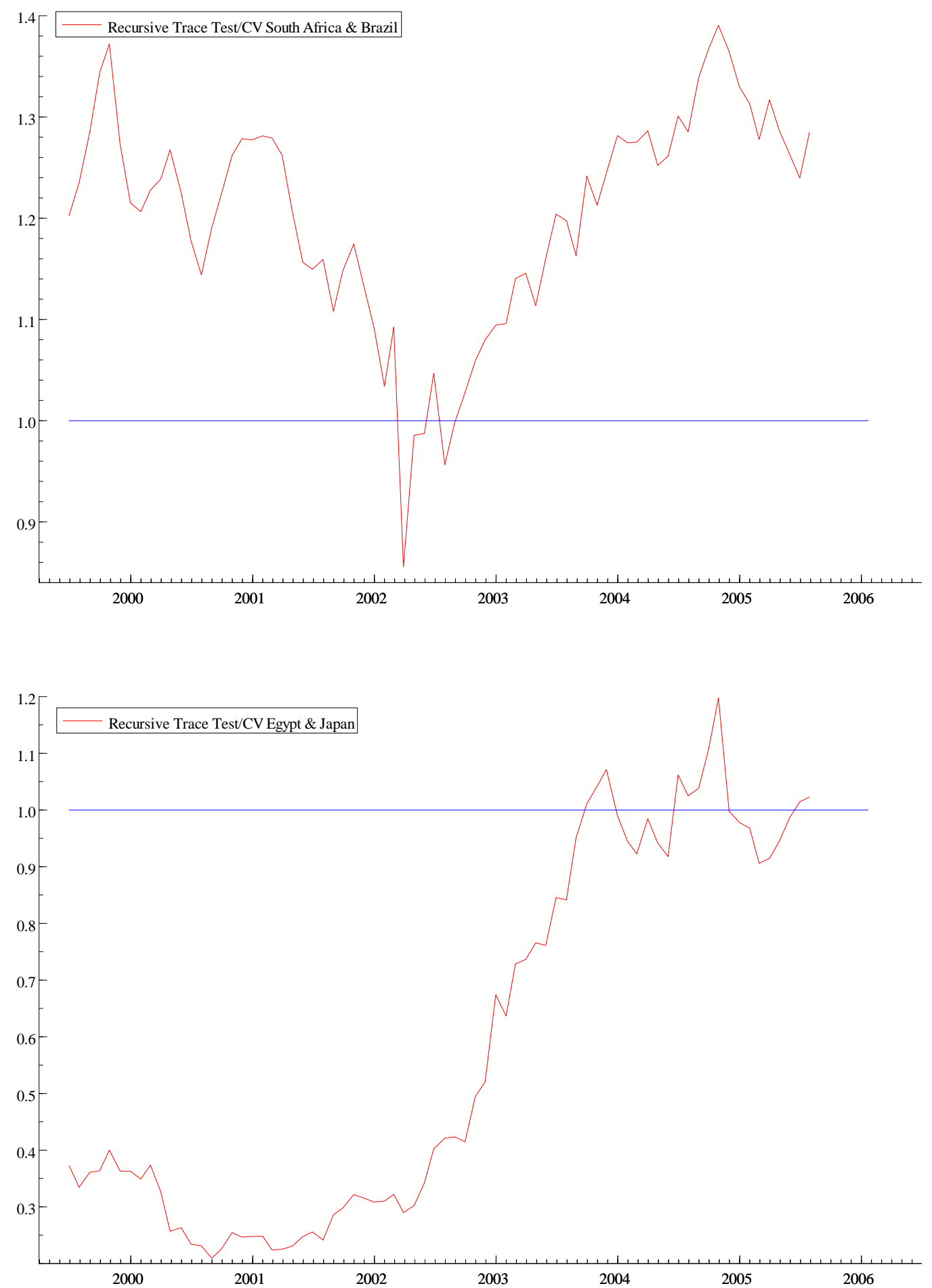


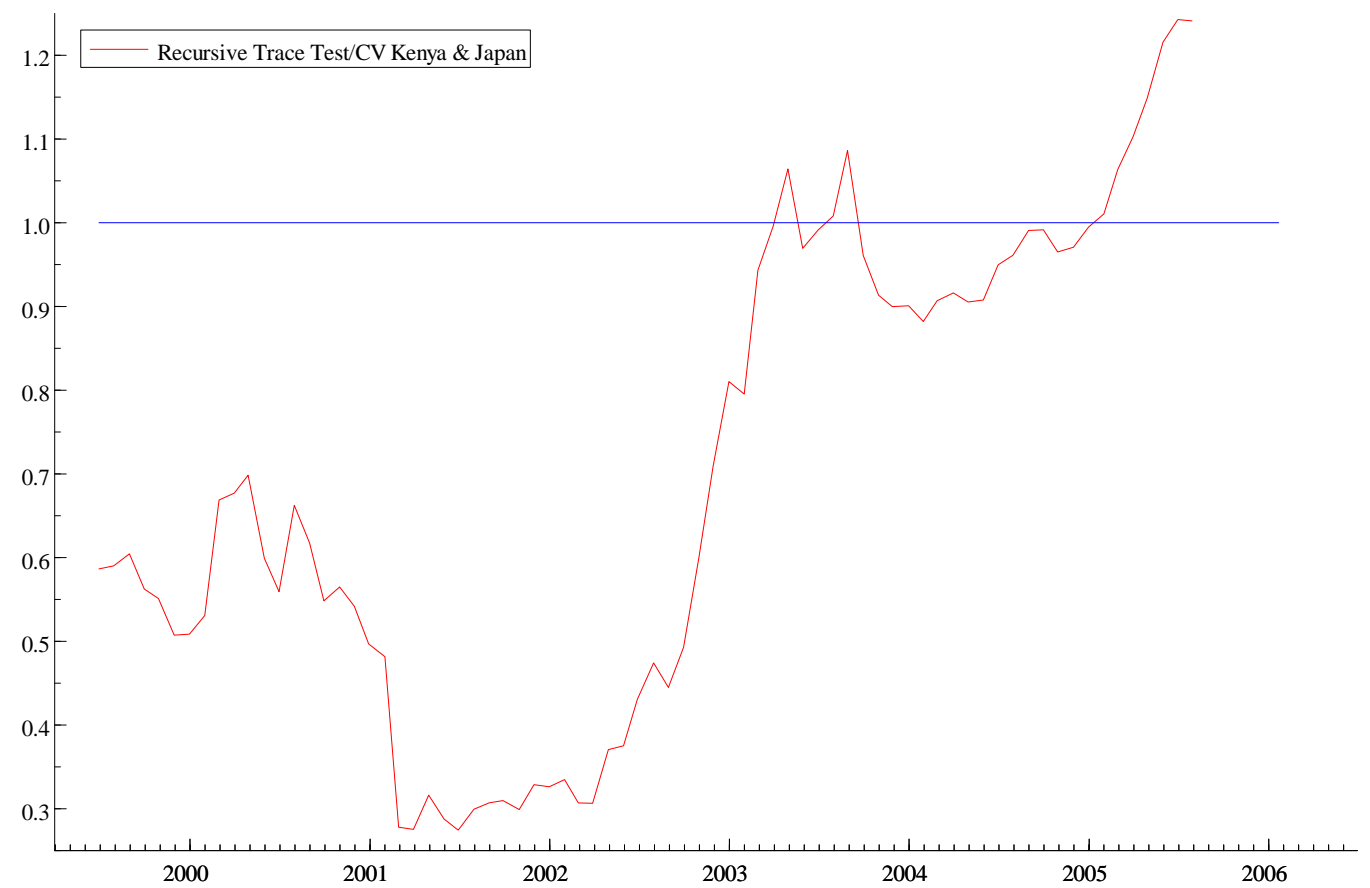

b) Breitung Test

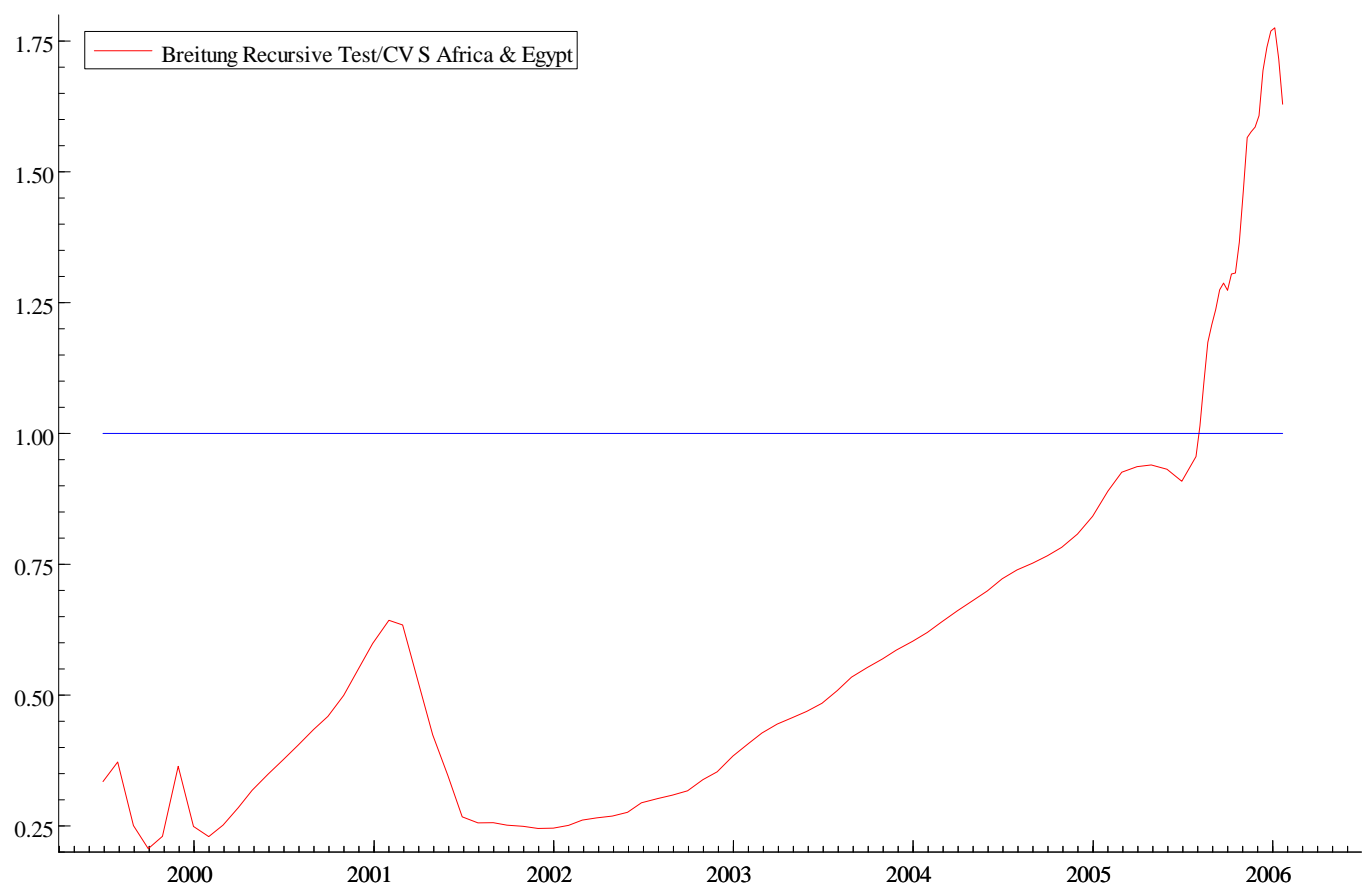




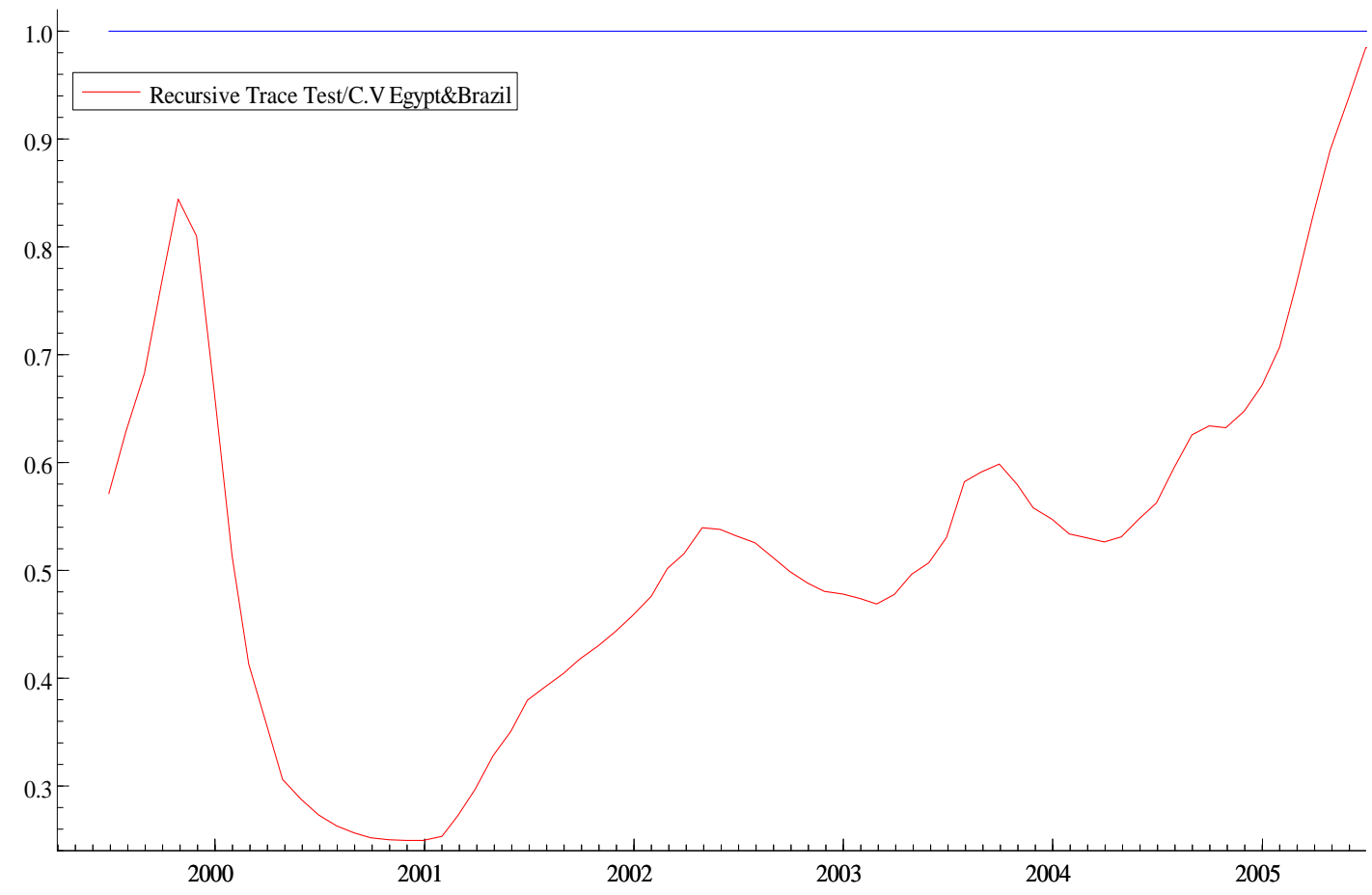




\section{Appendix}

Table 1: Estimated Long-run Correlations (Weekly Data)

\begin{tabular}{|c|c|c|c|c|c|c|c|c|c|}
\hline & Egypt & Kenya & Nigeria & South Africa & Brazil & Mexico & India & Japan & UK \\
\hline Kenya & 0.935 & & & & & & & & \\
\hline Nigeria & 0.780 & 0.741 & & & & & & & \\
\hline South Africa & 0.943 & 0.902 & 0.877 & & & & & & \\
\hline Brazil & 0.956 & 0.884 & 0.839 & 0.944 & & & & & \\
\hline Mexico & 0.924 & 0.848 & 0.904 & 0.970 & 0.960 & & & & \\
\hline India & 0.955 & 0.905 & 0.855 & 0.969 & 0.973 & 0.963 & & & \\
\hline Japan & 0.578 & 0.571 & 0.063 & 0.443 & 0.519 & 0.386 & 0.518 & & \\
\hline UK & 0.793 & 0.801 & 0.429 & 0.724 & 0.773 & 0.698 & 0.768 & 0.858 & \\
\hline US & 0.583 & 0.585 & 0.169 & 0.483 & 0.589 & 0.470 & 0.554 & 0.904 & 0.921 \\
\hline
\end{tabular}

Table 2: $p$-values of the Estimated Long-run Correlations (Weekly Data)

\begin{tabular}{|c|c|c|c|c|c|c|c|c|c|}
\hline & Egypt & Kenya & Nigeria & South Africa & Brazil & Mexico & India & Japan & UK \\
\hline Kenya & 0.000 & & & & & & & & \\
\hline Nigeria & 0.000 & 0.000 & & & & & & & \\
\hline South Africa & 0.000 & 0.000 & 0.000 & & & & & & \\
\hline Brazil & 0.000 & 0.000 & 0.000 & 0.000 & & & & & \\
\hline Mexico & 0.000 & 0.000 & 0.000 & 0.000 & 0.000 & & & & \\
\hline India & 0.000 & 0.000 & 0.000 & 0.000 & 0.000 & 0.000 & & & \\
\hline Japan & 0.000 & 0.000 & 0.039 & 0.000 & 0.000 & 0.000 & 0.000 & & \\
\hline UK & 0.000 & 0.000 & 0.000 & 0.000 & 0.000 & 0.000 & 0.000 & 0.000 & \\
\hline US & 0.000 & 0.000 & 0.000 & 0.000 & 0.000 & 0.000 & 0.000 & 0.000 & 0.000 \\
\hline
\end{tabular}

